\title{
The Research of Interpersonal Conflict and Solution Strategies
}

\author{
Yingshan Bao1,2, Fangwei Zhu' ${ }^{1}$, Yue $\mathrm{Hu}^{2}$, Ning Cui ${ }^{3}$ \\ ${ }^{1}$ Faculty of Management and Economics, Dalian University of Technology, Dalian, China \\ ${ }^{2}$ Psychologyical Health Education and Counseling Centre, Dalian University of Technology, Dalian, China \\ ${ }^{3}$ Institute of Research of Ideological and Political Theory, Changchun University of Chinese Medicine, \\ Changchun, China \\ Email: 157260784@qq.com
}

Received 5 March 2016; accepted 18 April 2016; published 21 April 2016

Copyright (C) 2016 by authors and Scientific Research Publishing Inc.

This work is licensed under the Creative Commons Attribution International License (CC BY).

http://creativecommons.org/licenses/by/4.0/

(c) (i) Open Access

\begin{abstract}
Conflict is an inevitable fact of human existence. This paper makes a definition of interpersonal conflict, and promotes some interpersonal communication skills as effective for the resolution of conflict. If we work to understand and resolve it effectively, we can improve both the satisfaction and productivity of our social relationships.
\end{abstract}

Keywords

Interpersonal Conflict, Resolution, Strategies

\section{Introduction}

We all live in a network which is changing and associated of family members, colleagues, friends and schoolmates. In the majority of cases, we can find ways to get along with each other. But occasionally, there always exists a situation that a roommate occupies the restroom for too long time, or disturbs you. When the conflicts for goals, actions, beliefs, opinions and competition for limited resources or miscommunications and misunderstandings occur, the interpersonal conflict may be inevitable. Nowadays, interpersonal conflict has become one of the most important concerns of researchers and writers especially those who are studying organizational behavior. Interpersonal conflict was observed to be an important topic for both managers and scientists who are interested in understanding the nature of organizational behavior and organizational processes. Conflict was also claimed as an important theme for study in both business organizations and non-business organizations, including the higher education institutions.

Schermerhorn (1993) claimed that everyone has to face with interpersonal conflict and it is very commonly 
experienced by managers. One research shows that managers spent about 20 percent of their time in conflict management (Thomas \& Schmidt, 1976). The fact that the superior and middle managers use two hours of their daily time in solving confliction situations has been revealed by the American Management Association. Studies show that college-educated adults are not good at dealing with interpersonal conflicts in work (Gardner \& Lambert, 1993; Volkema \& Bergmann, 1995). In a study about the conflicts of young adult women, it was found in the result that most women reported being troubled by work-related conflicts, and responding conformably to them (Weitzman, 2000). Interpersonal conflict for job is regarded as one of the top occupational working pressure sources (Narayanan, Menon, \& Spector, 1999; Newton \& Keenan, 1985; Rainey, 1995; Stewart \& Ellery, 1998), and strongly related to a reduction in worker mental and physical health. Employees involved in conflict miss an average of $6 \%$ more work, and pay out an average of $50 \%$ more in healthcare costs than employees reporting no conflict (Kittusamy \& Buchholz, 2004; Raak \& Raak, 2003). In addition, interpersonal conflict for job has been identified as a determinant factor of work disability (Appelberg, Romanov, Heikkilä, Honkasalo, \& Koskenvuo, 1996) and a predictor of workplace accidents (Oi-Ling, Phillips, \& Tat-Wing, 2004). The frequency with which interpersonal conflict is reported to occur at work gives additional importance to these findings. Some researches described that the frequency of incidents of interpersonal conflict at work ranged from $25 \%$ to $50 \%$ of an employee's work day (Hahn, 2000). This study was to explore the interpersonal conflicts and their resolution strategies. It can effectively help people to better face the conflict, deal with conflict and resolve conflicts, and promote the interpersonal relationships.

\section{Definition of Interpersonal Conflict}

The concept of conflict is called wenti (problem), maodun (contradiction), chongtu (clash), zhengzhi/zhenglun (dispute), fenqi (difference) and butong yijian (disagreement), which are most usually used by Chinese people to describe conflict. All these words have a strong hostile connection and involve negative emotions in the Chinese interpretation. In western literature, the conflict is considered as a series of disagreement or incompatibility between opinions and principles (Jehn \& Bendersky, 2003). People view it as interference or blocking behavior. Others believe it as negative emotions, such as stress, anxiety, depression and anger (Bodtker \& Jameson, 2001; Pondy, 1967; Thomas, 1992). What is more, some people believe that the conflict is the perception of different interests. It refers to the idea that involves the beliefs of different social entities (i.e., individual, group, organisation, etc.) who perceive incompatible goals and interference from others in achieving those goals (Rahim, 2010; Tjosvold, 1990).

No ideal definition for interpersonal conflict. Different researchers have different views about "Interpersonal conflict" based on their researches. Kellermann (1996) believed that interpersonal conflict can be simply described as a clash between two individuals who are unwillingly or unable to fulfill expectations of each other. Interpersonal conflict refers to the representation of incompatibility, disagreement, or difference between two or more interacting individuals (Rahim, 2001). Hocker \& Wilmot (2007) in their book define interpersonal conflict as "An expressed struggle between at least two interdependent parties who perceive incompatible goals, scarce resources, and interference from the other party in achieving their goals".

After reviewing some of the recent definitions of interpersonal conflict, I summarized Interpersonal conflict as an interaction of interdependent people who sense disagreement and opposing interests, incompatibility and the possibility of interference, and negative emotion from others.

\section{Interpersonal Conflict Resolution Strategies}

Conflict is inevitable. It is negative when it leads to violence, undermines the communication relationship between the parties involved in the conflict, stimulates people to become uncooperative, or prevents the parties from addressing real issues or problems. However, the conflict can be a positive creative force, when it increases communication, releases stored feelings, leads to the solution of problems, results in the growth of the relationship between parties in conflict, or improves performance.

Result of the conflict depends on the way it solves. Just as there are many sources of conflict, people choose different ways to deal with. Some try to avoid conflict as much as possible they can. They believe that the conflict is a signal problems in their relationships, they think a "nice" people do not experience conflict, or that conflict will inevitably bring frustration, anger or anxiety.

This approach may prove to be ineffective for two reasons. First, conflict is inevitable. In any form of interac- 
tion, people will have a different opinion or want something different, and this is no problem. In fact, the "negative" emotions in human interaction is a threat, but it is very important manner.

When using a positive and constructive manner to resolve conflicts, they might bring reconciliation and to meet the individual needs of comfort, intimacy update and strengthen the faith, so that people can be more cooperation and overcome difficulties.

There are many different strategies to handling conflict; however, not all of them are wise strategies. According to Floyd (2009), "Our choices almost always have an effect on our relationships". Most of us use conflict skills that we observed growing up, unless we have made a conscious effort to change our conflict resolution style. Some of us observed good conflict resolution, while others observed faulty conflict resolution. Therefore, it is important to learn, and practice effective conflict resolution strategies. The conflict resolution strategy you chose to apply will have an effect on your relationships with others. Conflict does not damage relationships, poor resolution of conflict does. Interpersonal conflict resolution is a permanent solution to the problem or dispute through dialogue, without physical or verbal violence.

\section{Strategies for Resolving Conflict}

Here are some methods in life skills to effectively deal with interpersonal conflict, conflict resolution in this study provide some effective interpersonal communication skills.

\subsection{Treat Others Respectfully}

One way of dealing with conflict have a major impact on the relationship between the results. People assess conflict behavior of others abilities. If a person can manage conflict, respect for that person. If a man becomes very angry, and even use violence to resolve conflict, people will condemn this person. In the debate, even if it is hard to see the benefits of your opponent, but remember talking about the living, he or she wants to be appreciated and respected thing is very important. What's more, when people feel heard, they tend to respond. People perceive those who understand them as smart and caring, and therefore, as also worth listening to. So, only you respect others, others will treat you the same way.

\subsection{Set the Right Tone for the Conversation}

Tone of conversation throughout the conflict resolution process may have a huge impact. It is important to know that both sides have the will to resolve the conflict, rather than fighting. It can be a good idea to spend some time on things unrelated to the conflict and expressed your appreciation for your counterpart's willingness to cooperate. You may say, such as "Thank you for committing your time to this issue," "I really appreciate that we can talk about this problem," or "I'd like to hear your thoughts on this situation." Which may help to agree on some rules for discussion.

\subsection{Active Listening}

One of the obstacles to solve a conflict efficiently is a human tendency to "listen ahead". This means that during a conversation our own thoughts about what a speaker says cause us to jump to conclusions about what the person is trying to say. Once we think we "know" it, we do not further listen to what is really being said. We can also start thinking about what we're going to say in response, and thereby stop listening. Fortunately, Active listening is a skill, and it can be practiced. One exercise to try is talking with a friend about a topic you disagree on. Let your friend talk for about two minutes. After two minutes, tell your friend how you understood his or her opinion. The feedback can involve paraphrasing what you think the speaker said, and asking questions to clarify. It should not include an evaluation of, or a counter-argument to, what the speaker said; When discussing a controversial topic, take time to repeat what the other person said. It will help you to comprehend your counterpart's point of view as well as avoid miscommunication.

\subsection{Perspective Taking}

Brown (1965) emphasizes that all successful interpersonal communication requires that the point of view of the other person be realistically understood, Perspective taking is largely an internal process, fostered by active lis- 
tening, in which you try to understand how it might feel to be the other person in the situation. In other words, perspective taking is trying to understand the other person's needs, concerns, difficulties, and pain in this situation to a similar extent as you understand your own needs, concerns, etc. Both Brown and Deutsch have pointed out that mastering the ability to understand the other person's perspective, however, is worth the effort in that it can lead to more open and trusting communication. When a person in a conflict tries to communicate openly and be inclusive of the other person's point of view and needs, it will likely induce the same communicative behaviors on the part of the other person (Deutsch, 2000).

\subsection{Avoid Negative Attributions}

Imagine that you are driving a car. The light turns green and you have not yet accelerated when a driver behind you honks their horn. What would your reaction be? Would you be upset with the other driver rushing you in such a rude way? If yes, you would be making a negative attribution, or in other words, you would find a negative explanation for the other driver's behavior. Making negative attributions is a common source of conflicts and a serious obstacle in solving them. However, it is also easy to avoid them by temporarily withholding your judgments and checking what someone's motives actually were. The situation described above actually happened to my friend, and she got very angry at the other car's driver. Imagine her surprise when later on she found out that the other driver was in fact her friend who, by honking, wanted to get her attention to say "Hi." So, before you get angry, make sure that you have a sound reason for it.

\subsection{Solve Conflicts When They Are Small}

Many people think that the conflict will not go away. In most cases, an untouched conflict over time, resentment and negative emotions will increase. Besides, when the emotions are intense, and the causes of the conflict are unclear because time has passed from the first incident, it is much more difficult to deal with.

Interpersonal conflict in human interaction is inevitable. If we are able to understand and solve it effectively, we can improve satisfaction and productivity of our social relations.

\section{Funding}

Supported by Fundamental Research Funds for the Central Universities of China (Grant No. DUT14RW103); Social Science Foundation of Liaoning Province of China (Grant No. L15CFX007); "the twelfth five" planning project of educational science of Liaoning Province of China (Grant No. JGZXS13003).

\section{References}

Appelberg, K., Romanov, K., Heikkilä, K., Honkasalo, M., \& Koskenvuo, M. (1996). Interpersonal Conflict as a Predictor of Work Disability: A Follow-Up Study of 15,348 Finnish Employees. Journal of Psychosomatic Research, 40, 157-167. http://dx.doi.org/10.1016/0022-3999(95)00576-5

Bodtker, A. M., \& Jameson, J. K. (2001). Emotion in Conflict Formation and Its Transformation: Application to Organizational Conflict Management. International Journal of Conflict Management, 12, 259-275. http://dx.doi.org/10.1108/eb022858

Deutsch, M. (2000). The Handbook of Conflict Resolution. San Francisco: Jossey-Bass.

Gardner, P. D., \& Lambert, S. E. (1993). It's a Hard, Hard, Hard, Hard, Hard, Hard World. Journal of Career Planning \& Employment, 53, 40-49.

Hahn, S. E. (2000). The Effects of Locus of Control on Daily Exposure, Coping and Reactivity to Work Interpersonal Stressors: A Diary Study. Personality \& Individual Differences, 29, 729-748. http://dx.doi.org/10.1016/S0191-8869(99)00228-7

Jehn, K. A., \& Bendersky, C. (2003). Intragroup Conflict in Organizations: A Contingency Perspective on the ConflictOutcome Relationship. Research in Organizational Behavior, 25, 187-242. http://dx.doi.org/10.1016/S0191-3085(03)25005-X

Kittusamy, N. K., \& Buchholz, B. (2004). Whole-Body Vibration and Postural Stress among Operators of Construction Equipment: A Literature Review. Journal of Safety Research, 35, 255-261. http://dx.doi.org/10.1016/j.jsr.2004.03.014

Narayanan, L., Menon, S., \& Spector, P. E. (1999). Stress in the Workplace: A Comparison of Gender and Occupations. Journal of Organizational Behavior, 20, 63-73.

http://dx.doi.org/10.1002/(SICI)1099-1379(199901)20:1<63::AID-JOB873>3.0.CO;2-J 
Newton, T. J., \& Keenan, A. (1985). Coping with Work-Related Stress. Human Relations, 38, 107-126. http://dx.doi.org/10.1177/001872678503800202

Oi-Ling, S., Phillips, D. R., \& Tat-Wing, L. (2004). Safety Climate and Safety Performance among Construction Workers in Hong Kong: The Role of Psychological Strains as Mediators. Accident Analysis \& Prevention, 36, 359-366. http://dx.doi.org/10.1016/S0001-4575(03)00016-2

Pondy, L. R. (1967). Organizational Conflict: Concepts and Models. Administrative Science Quarterly, 13, $296-320$. http://dx.doi.org/10.2307/2391553

Raak, R., \& Raak, A. (2003). Work Attendance Despite Headache and Its Economic Impact: A Comparison between Two Workplaces. Headache: The Journal of Head \& Face Pain, 43, 1097-1101. http://dx.doi.org/10.1046/j.1526-4610.2003.03212.x

Rahim, M. A. (2010). Managing Conflict in Organizations. Piscataway, NJ: Transaction Publishers.

Rainey, D. (1995). Sources of Stress among Baseball and Softball Umpires. Journal of Applied Sport Psychology, 7, 1-10. http://dx.doi.org/10.1080/10413209508406296

Schermerhorn, J. R. (1993). Management for Productivity. Hoboken, NJ: John Wiley \& Sons Inc.

Stewart, M. J., \& Ellery, P. J. (1998). Sources and Magnitude of Perceived Psychological Stress in High School Volleyball Officials. Perceptual \& Motor Skills, 87, 1275-1282. http://dx.doi.org/10.2466/pms.1998.87.3f.1275

Thomas, K. W. (1992). Conflict and Conflict Management: Reflections and Update. Journal of Organizational Behavior, 13, 265-274. http://dx.doi.org/10.1002/job.4030130307

Thomas, K. W., \& Schmidt, W. H. (1976). A Survey of Managerial Interests with Respect to Conflict. Academy of Management Journal, 19, 315-318. http://dx.doi.org/10.2307/255781

Tjosvold, D. (1990). Defining Conflict and Making Choices about Its Management: Lighting the Dark Side of Organizational Life. International Journal of Conflict Management, 17, 87-95. http://dx.doi.org/10.1108/10444060610736585

Volkema, R. J., \& Bergmann, T. J. (1995). Conflict Styles as Indicators of Behavioral Patterns in Interpersonal Conflicts. Journal of Social Psychology, 135, 5-15. http://dx.doi.org/10.1080/00224545.1995.9711395

Weitzman, P. F. (2000). Brief Report: Young Adult Women Resolving Interpersonal Conflicts. Journal of Adult Development, 8, 61-67. http://dx.doi.org/10.1023/A:1026402022035 